(2) Open Access Full Text Article

\title{
A possible pathological link among swallowing dysfunction, gastro-esophageal reflex, and sleep apnea in acute exacerbation in COPD patients
}

This article was published in the following Dove Press journal:

International Journal of COPD

27 January 2016

Number of times this article has been viewed

\section{Shinji Teramoto}

Department of Pulmonary Medicine, Hitachinaka Medical Education and Research Center, University of Tsukuba, Ibaraki, Japan
Correspondence: Shinji Teramoto Hitachinaka Medical Education and Research Center, University of Tsukuba, 20-I Hitachinaka-shi, Ibaraki, 3|2-0057, Japan

$\mathrm{Tel}+8 \mid 293545$ III

Fax+8I 293545926

Email shinjit-tky@umin.ac.jp

\section{Dear editor}

With interest, we read the review article by Lee and Goldstein ${ }^{1}$ published in the recent issue of the International Journal of Chronic Obstructive Pulmonary Disease. The authors have comprehensively summarized the possible roles of gastroesophageal reflux disease (GERD) in a variety of aspects of pathogenesis of COPD. However, the considerable associations among GERD, swallowing dysfunction, sleep apnea, and acute exacerbation (AE) of COPD have not been fully discussed.

GERD-related chronic cough (CC) may have multifactorial causes. GER is known to induce esophagopharyngeal reflux (EPR), resulting in CC. Importantly, symptoms of CC fully responded to full-dose proton pump inhibitor therapy in CC patients with GERD. ${ }^{2}$ There are evidences of increase of weakly acidic gas EPR and swallowinginduced acidic EPR in patients with COPD. ${ }^{3}$

The GERD and its related swallowing impairment may be closely associated with unwitnessed pulmonary aspiration, such as mis-swallowing or silent aspiration in older patients with COPD. Further, sleep apnea, which is relatively common in COPD patients, also causes GER and non-acidic reflux. The sleep apnea-related GER events also cause pulmonary aspiration that is accompanied with bronchial constriction and hypoxic responses in their lungs. Pulmonary aspiration is a risk factor for upper and lower respiratory tract infections in COPD patients.

We have previously reported that more than eight of 48 (16.7\%) COPD patients showed an abnormal swallowing function. ${ }^{4}$ In our experience, the higher prevalence of GER, abnormal swallowing reflex or sleep apnea has been investigated in COPD patients who experienced AE but not in those without AE. These three disorders are mainly related with the pathogenesis of each disease and contribute to inducing pulmonary infection and/or AE. ${ }^{5}$

From these points of view, GER may have a significant impact on the increased frequency of $\mathrm{AE}$ in patients with COPD. Thus GERD, swallowing dysfunction, and sleep apnea may be important risk factors for AE through the pulmonary aspirationrelated events in COPD patients.

\section{Disclosure}

The author report no conflicts of interest in this communication. 


\section{References}

1. Lee AL, Goldstein RS. Gastroesophageal reflux disease in COPD: links and risks. Int J Chron Obstruct Pulmon Dis. 2015:10:1935-1949.

2. Kawamura $\mathrm{O}$, Shinoyama $\mathrm{Y}, \mathrm{Hosaka} \mathrm{H}$, et al. Increase of weakly acidic gas esophagopharyngeal reflux (EPR) and swallowing-induced acidic/ weakly acidic EPR in patients with chronic cough responding to proton pump inhibitors. Neurogastroenterol Motil. 2011;23(5):411-e172.
3. Kristo I, Riegler M, Schoppmann SF. Laryngopharyngeal reflux COPD to uncover reflux and columnar lined esophagus. Int J Chron Obstruct Pulmon Dis. 2015;10:2095-2096.

4. Teramoto S, Kume H, Ouchi Y. Altered Swallowing Physiology and Aspiration in COPD. Chest. 2002;122(3):1104-1105.

5. Teramoto S, Ishii T, Matsuse T. Chronic cough, sleep apnea, and gastroesophageal reflux disease. Chest. 2001;120(3):1036-1037. 


\section{Author reply}

Annemarie L Lee ${ }^{1-3}$

Roger S Goldstein ${ }^{1,2,4}$

'Department of Respiratory Medicine, West Park Healthcare Centre, Toronto, ON, Canada; ${ }^{2}$ Department of Physical Therapy, University of Toronto, Toronto, ON, Canada; ${ }^{3}$ Institute for Breathing and Sleep, Austin Health, Melbourne, VIC, Australia; ${ }^{4}$ Department of Medicine, University of Toronto, Toronto, ON, Canada

Correspondence: Annemarie L Lee

Department of Respiratory Medicine, West Park Healthcare Centre, 82 Buttonwood Avenue, Toronto, ON, M6M 2J5, Canada

$\mathrm{Tel}+\mathrm{I} 4162432653$

Fax + I 4162433747

Email annemarie.lee@westpark.org

\section{Dear editor}

We thank Dr Teramoto for his interesting comments regarding the relationship between gastroesophageal reflux disease (GERD), swallowing dysfunction, sleep apnea, and acute exacerbation of COPD, in response to our review titled "Gastroesophageal reflux disease in COPD: links and risks".

We agree that pulmonary aspiration with respect to swallowing dysfunction in COPD is a possibility. With swallowing comprised of four stages, any lack of coordination of these movements introduces the risk of laryngeal penetration and subsequently laryngotracheal aspiration. ${ }^{1}$ Individuals with COPD exhibit disrupted coordination of the respiratory cycle with deglutition, with dyspnea and as a result of abnormalities in thoraco-abdominal biomechanics, contributing to dissynchrony and possible dysphagia. ${ }^{2}$ Swallowing dysfunction and altered reflexes with laryngeal aspiration ${ }^{3}$ may predispose individuals to acute exacerbations, with a relative risk of 2.8 (95\% confidence interval $1.5-5.0) .^{4}$ The presence of swallowing abnormalities during a stable phase of COPD was linked to a higher risk of developing exacerbations in the following year. ${ }^{5}$ A significant proportion of individuals hospitalized with an exacerbation of COPD have a coexisting oropharyngeal swallowing disorder, ${ }^{6}$ which may contribute to or exacerbate their disease.

Previous work has also highlighted the link between nocturnal GER symptoms, symptoms of obstructive sleep apnea (OSA), and a reduced forced expiratory volume in 1 second/forced vital capacity in those with $\mathrm{COPD}^{7}$ and a higher prevalence of OSA in those with COPD and GERD. ${ }^{8}$ Proposed causative mechanisms include a lower baseline lower esophageal sphincter (LES) pressure in individuals with OSA, possibly from repetitive strain associated with upper airway obstruction, ${ }^{9}$ a higher frequency of transient LES relaxation during sleep related to preceding arousals and shallow sleep, ${ }^{10}$ and LES insufficiency. ${ }^{11}$

With up to a third of severe exacerbations not attributed to respiratory infection or air pollution, ${ }^{12}$ impaired coordination between breathing and swallowing may be a key aggravating or causative factor of acute exacerbations in some individuals. Although confirmation is required, this triad of comorbidities (GERD, OSA, and swallowing dysfunction) may heighten the risk of pulmonary aspiration and subsequent acute exacerbation in COPD; the presence of these comorbidities should be considered in those experiencing recurrent acute exacerbations of COPD.

\section{Disclosure}

The authors report no conflicts of interest in this communication.

\section{References}

1. Gross RD, Atwood CW Jr, Ross SB, Olszewski JW, Eichhorn KA The coordination of breathing and swallowing in chronic obstructive pulmonary disease. Am J Respir Crit Care Med. 2009;179(7): 559-565.

2. Good-Fratturelli MD, Curlee RF, Holle JL. Prevalence and nature of dysphagia in VA patients with COPD referred for videofluorescopic swallow examination. J Commun Disord. 2000;33(2):93-110.

3. Cvejic L, Harding R, Churchward T, et al. Laryngeal penetration and aspiration in individuals with stable COPD. Respirology. 2011;16(2): 269-275.

4. Steidl E, Ribeiro CS, Goncalves BF, Fernandes N, Antunes V, Mancopes R. Relationship between dysphagia and exacerbations in chronic obstructive pulmonary disease. Int Arch Otorhinolaryngol. 2015; 19(1):74-79.

5. Kobayashi S, Kubo H, Yanai M. Impairment of the swallowing reflex in exacerbations of COPD. Thorax. 2007;62(11):1017.

6. Terada K, Muro S, Ohara T, et al. Abnormal swallowing reflex and COPD exacerbations. Chest. 2010;137(2):326-332.

7. Robinson D, Jerrard-Dunne P, Greene Z, Lawson S, Lane S, O’Neill D. Oropharyngeal dysphagia in exacerbations of chronic obstructive pulmonary disease. Eur Geriatric Med. 2011;2(4):201-203.

8. Emilsson OI, Janson C, Benediktsdottir B, Juliusson S, Gislason T. Nocturnal gastroesophageal reflux, lung function and symptoms of obstructive sleep apnea: Results from an epidemiological survey. Respir Med. 2012;106(3):459-466.

9. Shepherd K, Hillman D, Holloway R, Eastwood P. Mechanisms of nocturnal gastroesophageal reflux events in obstructive sleep apnea. Sleep Breath. 2011;15(3):561-570.

10. Kuribayashi S, Kusano M, Kawamura O, et al. Mechanism of gastroesophageal reflux in patients with obstructive sleep apnea syndrome. Neurogastroenterol Motil. 2010;22(6):611-672.

11. Demeter P, Pap A. The relationship between gastroesophageal reflux disease and obstructive sleep apnea. J Gastroenterol. 2004;39(9) 815-820.

12. Connors AF Jr, Dawson NV, Thomas C. Outcomes following acute exacerbation of severe chronic obstructive lung disease. The SUPPORT investigators. Am J Respir Crit Care Med. 1996;154(4 Pt 1):959-967. 
Dove Medical Press encourages responsible, free and frank academic debate. The content of the International Journal of Chronic Obstructive Pulmonary Disease 'letters to the editor' section does not necessarily represent the views of Dove Medical Press, its officers, agents, employees, related entities or the International Journal of Chronic Obstructive Pulmonary Disease editors. While all reasonable steps have been taken to confirm the content of each letter, Dove Medical Press accepts no liability in respect of the content of any letter, nor is it responsible for the content and accuracy of any letter to the editor.

International Journal of COPD

\section{Publish your work in this journal}

The International Journal of COPD is an international, peer-reviewed journal of therapeutics and pharmacology focusing on concise rapid reporting of clinical studies and reviews in COPD. Special focus is given to the pathophysiological processes underlying the disease, intervention programs, patient focused education, and self management protocols.

Dovepress

Submit your manuscript here: http://www.dovepress.com/international-journal-of-chronic-obstructive-pulmonary-disease-journal

This journal is indexed on PubMed Central, MedLine and CAS. The manuscript management system is completely online and includes a very quick and fair peer-review system, which is all easy to use. Visit http://www.dovepress.com/testimonials.php to read real quotes from published authors. 